Article

\title{
Resistance of Escherichia coli in Turkeys after Therapeutic or Environmental Exposition with Enrofloxacin Depending on Flooring
}

\author{
Bussarakam Chuppava ${ }^{1}$, Birgit Keller ${ }^{1}$, Amr Abd El-Wahab ${ }^{2}$, Jessica Meißner ${ }^{3}$, \\ Manfred Kietzmann ${ }^{3}$ and Christian Visscher ${ }^{1, *}$ \\ 1 Institute for Animal Nutrition, University of Veterinary Medicine Hannover, Foundation, \\ Bischofsholer Damm 15, D-30173 Hanover, Germany; bussarakam.chuppava@tiho-hannover.de (B.C.); \\ birgit.keller@tiho-hannover.de (B.K.) \\ 2 Department of Nutrition and Nutritional Deficiency Diseases, Faculty of Veterinary Medicine, \\ Mansoura University, Mansoura 35516, Egypt; amrabdelwahab37@yahoo.de \\ 3 Institute for Pharmacology, Toxicology, and Pharmacy, University of Veterinary Medicine Hannover, \\ Foundation, Bünteweg 17, D-30559 Hannover, Germany; jessica.meissner@tiho-hannover.de (J.M.); \\ manfred.kietzmann@tiho-hannover.de (M.K.) \\ * Correspondence: christian.visscher@tiho-hannover.de; Tel: +49-511-856-7415
}

Received: 27 July 2018; Accepted: 11 September 2018; Published: 13 September 2018

\begin{abstract}
Gaining knowledge about the spread of resistance against antibacterial agents is a primary challenge in livestock farming. The purpose of this study was to test the effect of double antibiotic treatment (at days 10-14 and days 26-30) with enrofloxacin or solely environmental exposition (identical times, directly into the litter) on resistance against antibacterial agents in commensal Escherichia coli in comparison with the control (without treatment), depending on different flooring. A total of 720 Big 6 turkeys participated in three trials. Four different flooring designs were examined: An entire floor pen covered with litter, a floor pen with heating, a partially slatted flooring including $50 \%$ littered area, and a fully slatted flooring with a sand bath. A total of 864 Escherichia coli isolates were obtained from cloacal swabs and poultry manure samples at days 2, 9, 15, 21, and 35 . The broth microdilution method (MIC) was used to determine the resistance of isolates to enrofloxacin and ampicillin. A double antibiotic treatment with enrofloxacin reduced the proportion of susceptible Escherichia coli isolates significantly in all flooring designs. Simulation of water losses had no significant effect, nor did the flooring design. Ampicillin-resistant isolates were observed, despite not using ampicillin.
\end{abstract}

Keywords: flooring design; Turkey; antibacterial resistance; enrofloxacin; commensal E. coli

\section{Introduction}

Resistance to antibacterial agents is an increasing problem in public health and veterinary medicine worldwide [1-3]. The major public health concern which has been expressed for several decades is still the potential for transmission of antibiotic-resistant bacteria from animals to humans [4]. Most of the amounts of antibiotics used (30-80\%) in livestock farming are excreted by the animals directly into the environment via urine and feces because of partial metabolization of antibacterial agents and residue in manure [5-7]. Resistance to antibacterial agents in Gram-negative bacteria is on the rise in pathogens as well as in commensal bacterial flora, particularly in Escherichia coli. E. coli constitutes the majority of invasive Gram-negative isolates for humans in European countries [8]. The natural habitat of $E$. coli is the gastrointestinal tract of mammals and birds [9]. It is considered as an 
indicator bacteria for resistance detection. E. coli also has the ability to survive in and adapt to various extra intestinal habitats and to spread resistances between humans, animals, and the environment [10].

Antibacterial agents in livestock production have been either used to prevent diseases and promote animal growth or for therapeutic purposes [11,12]. The total sales of veterinary antibacterial agents during 2015 in the European Union (EU) amounted to approximately 8361 tons [13]. The average antibacterial consumption by humans $(124 \mathrm{mg} / \mathrm{kg}$ ) was lower than in animals $(152 \mathrm{mg} / \mathrm{kg})$ [3]. The resistance level of avian isolates to E. coli in Germany, for example, exceeded the level determined by the Federal Office of Consumer Protection and Food Safety for other veterinary pathogens in other animal species [14]. In the past, in relation to their respective fattening periods, in poultry, antibacterial agents have been used more often and for a longer duration compared with cattle and pigs [15].

Fluoroquinolones (FQ) have been classified as being critically important for human health and animal farms by the World Health Organization [4]. An unfavorable situation has arisen in Europe: Resistance to these antibiotics is widespread and the incidence of resistance increased significantly between 2012 and 2015 [3]. The application of FQ agents in poultry husbandry has led to increasing problems with resistance to antibacterial agents $[16,17]$. The level of fluoroquinolone consumption showed a significant correlation with antibiotic resistance in $E$. coli in livestock husbandry $[3,18,19]$. In turkeys, commensal and pathogenic E. coli are often resistant to quinolones, including enrofloxacin, and to $\beta$-lactams $[2,13]$. Commensal E. coli isolates gained from turkey meat in Germany showed higher rates of resistance to FQ than E. coli from broilers [20].

In commercial poultry meat production in Europe, turkeys are reared on littered concrete floor. During the fattening period, the primary litter material becomes mixed with poultry excreta, feathers, feed, and spilt drinking water [21], the resulting mixture being referred to as poultry manure. Therefore, close contact with their litter or rather manure is common for turkeys during their productive life. More than $95 \%$ of the dry matter in manure consists of excreta [22]. This material can contain residues of antibacterial agents as well as resistant bacteria [17]. On almost every farm (62.3\%), E. coli can be isolated from manure [23]. The poultry environment has long been acclaimed as a potential source of antibiotic-resistant bacteria [5,17], acting as a possible reservoir for the dissemination of these organisms to humans via the food chain (poultry meat), person-to-person contact (food handlers), and environment (poultry waste disposal, organic fertilizers). A significant proportion of these antibiotics is excreted unchanged in animal urine and feces. These antibiotics can remain potent for a longer time in manure during storage $[5,24]$.

Information concerning the effects of separating animals from their excreta on the development of resistance to antibacterial agents in commensal $E$. coli in rearing turkeys has only been described in the study by Chuppava et al. [25]. The aim of the present study was to evaluate the effect of double antibiotic treatment (at days 10-14 and at days 26-30) with enrofloxacin or solely environmental exposition (at days 10-14 and days 26-30 directly into the litter) on resistance against antibacterial agents in commensal Escherichia coli in comparison with the control (without treatment), depending on different flooring. The different types of flooring design were distinguished by means of the contact intensity of birds to their excreta.

\section{Materials and Methods}

The animal experiments were conducted in accordance with the corresponding German regulations and approved by the Ethics Committee of Lower Saxony for Care and Use of Laboratory Animals (LAVES) (Niedersächsisches Landesamt für Verbraucherschutz und Lebensmittelsicherheit; reference: 33.12-42502-04-15/2044).

\subsection{Design of Experiments}

A total of 720 female one-day-old turkeys (B.U.T. Big 6) were obtained from a commercial hatchery (Heidemark GmbH, Ahlhorn, Germany). A total of three independent experiments (T1-T3) were carried out. For each of these experiments, 240 birds were used. 
Before starting the experiments in the second week after hatch, the birds were housed in dry and clean floor pens in a quarantine stable. Flooring was covered with wood shavings (GOLDSPAN ${ }^{\circledR}$, Goldspan GmbH and Co. KG, Goldenstedt, Germany). A commercially prepared pelleted diet was offered ad libitum (Best 3 Geflügelernährung GmbH, Twistringen, Germany).

Each experiment was started after the above described one-week adaptation period. For these experiments, specially manufactured boxes were used, twelve experimental pens $(1.20 \times 0.80 \mathrm{~m})$ in total. Different flooring designs were used to establish different degrees of contact intensity of the animals to the manure (Figure 1).
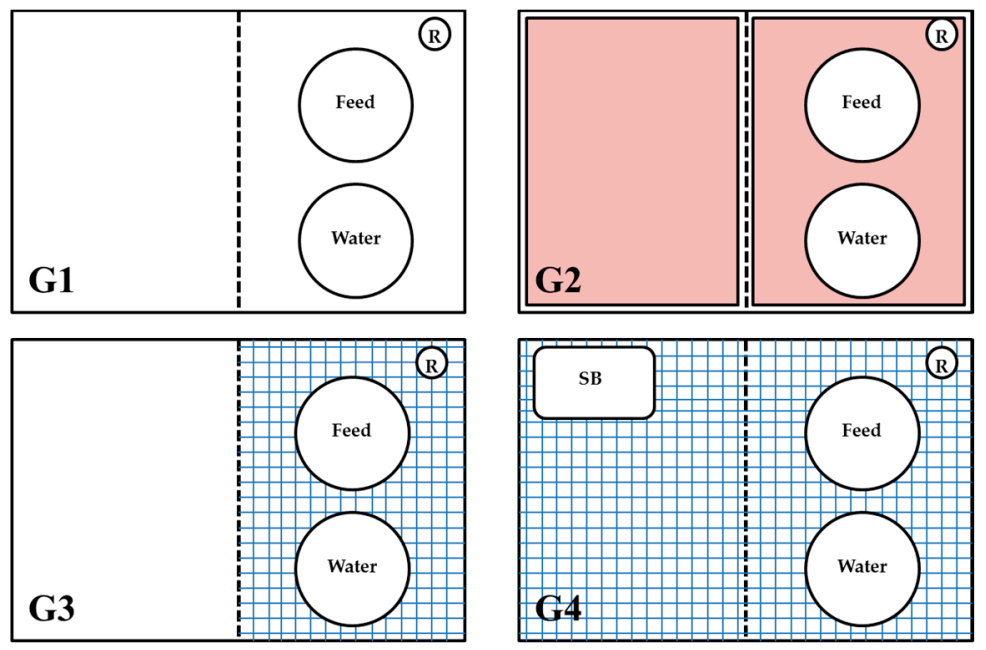

Figure 1. Flooring designs used in the study: G1 = entire floor pen with litter; G2 = identical to G1 and additionally having floor heating (in red); G3 = plastic covered steel slats in 50\% of the pen (in blue) as well as an area with litter; G4 = fully-slatted flooring with plastic covered steel slats and a sand bath $\left(900 \mathrm{~cm}^{2}\right)$. SB = sand bath, $\mathrm{R}=$ rope.

The first group served as a control. Animals were kept on dry wood shavings (G1—entire floor pen covered with litter). The second group was identically kept. The exception was an electrical floor heating system (Sauerland GmbH, Paderborn-Elsen, Germany) with an adjuster to control the temperature (G2-floor pen with litter with floor heating). Animals in these two groups continuously had full contact with manure. The pens in the third group (G3) were divided into two equal parts consisting of $50 \%$ solid flooring with wood shavings on the right-hand side and $50 \%$ plastic slatted flooring on the left-hand side. In the last group (G4), plastic slatted flooring with a sand bath $\left(900 \mathrm{~cm}^{2}\right)$ was used, the bath being disinfected and the sand replaced on a daily basis. Animals in G4 had no contact with litter except possibly in the sand bath. Plastic covered steel slats consisted of holes $(15 \times 10 \mathrm{~mm})$ and bridges (plastic covered steel; $3.5 \mathrm{~mm}$ wide; Big Dutchman International $\mathrm{GmbH}$, Vechta, Germany). The excreta were stored under the slatted floor at a depth of approximately $30 \mathrm{~cm}$ without any material being removed during the trial, besides small amounts of material needed for the samples as described below.

The boxes were placed in a randomized sequence in blocks of four subgroups (G1-G4) in the same stable, as previously described [25]. Two boxes of each block were placed on the right-hand side and two on the left-hand side of a central corridor ( $1.70 \mathrm{~m}$ width). Airing was provided by vacuum air ventilation. This system was installed in the ceiling in two rows above the pens. Wood shavings were used as bedding material $\left(1 \mathrm{~kg} / \mathrm{m}^{2}\right)$. Stocking densities reached a maximum of $25 \mathrm{~kg} / \mathrm{m}^{2}$. Hanging type feeders were used (Klaus Gritsteinwerk GmbH \& Co. KG, Bünde, Germany) as well as bell drinkers (Ferdinand Stükerjürgen GmbH \& Co. KG, Rietberg-Varensell, Germany).

Before commencing with the trials one week after hatch, stables and all materials had been disinfected. Also, tests had been performed to exclude the occurrence of Enterobacteriaceae. All birds were allocated to four groups, each with three identical subgroups $(\mathrm{n}=20 \mathrm{birds})$. Rearing was done 
until day 36. The birds had unlimited access to fresh water and feed (commercial pelleted growing diet). The environmental temperature was gradually reduced from about $33^{\circ} \mathrm{C}$ for the one-day-old birds to about $20^{\circ} \mathrm{C}$ by day 36. Lights were continuously on between days 1 and 3 and the photoperiod from day 4 onwards amounted to $16 \mathrm{~h}$ of light and $8 \mathrm{~h}$ of darkness.

In T1 there was no antibiotic treatment. This experiment served as a nontreated control trial. In contrast, animals in T2 were medicated with Baytril ${ }^{\circledR} 10 \%$ in drinking water $(10 \mathrm{mg}$ enrofloxacin $/ \mathrm{kg}$ body weight per day-corresponding to an addition of $0.5 \mathrm{~mL}$ Baytril ${ }^{\circledR} 10 \% / \mathrm{L}$ of drinking water, in accordance with the recommended dosage; Bayer Vital $\mathrm{GmbH}$, Leverkusen, Germany). In the last trial (T3), the birds were not treated with any antibiotic in drinking water. Spillage of drinking water containing enrofloxacin was simulated. The amount of water losses was calculated according to experience from former trials, comparing water intake in turkeys using drinking bowls and nipple drinkers (data not shown). Water containing enrofloxacin (dosage: $0.5 \mathrm{~mL} / \mathrm{L}$ of Baytril ${ }^{\circledR}$ $10 \%$, amount $240 \mathrm{~mL}$ per day) was sprayed into the litter or on the slatted flooring only in the feeding area. Both, in T2 and T3, five-day treatments were performed at days 10-14 and days 26-30.

At the end of day 21, eight out of 20 birds in each subgroup were dissected. Final dissection for all remaining turkeys $(n=12 /$ box) was done at day 36 . The stunning method (percussive blow to the head) was conducted in accordance with Annex I of the Council Regulation (EC) No. 1099/2009, Chapter I, Methods, Table 1—Mechanical Methods [26].

\subsection{Collection of Cloacal Swabs and Manure Samples}

Samples (864 in total) were taken before treatment, directly after antibiotic treatment and at the end of the trial. Cloacal swabs were collected at day 2 and manure samples at day 9 before treatment (BT: before treatment stage). After the enrofloxacin treatment (AT), at day 15, manure samples were taken and six days later, cloacal swabs were taken (day 21). Final sampling (ET) was done for both (manure and cloacal swabs) at day 35. Cloacal swabs were always collected from 24 animals per group, i.e., in total, 96 randomly selected animals. Six samples from each type of flooring design (two samples per pen), in total 24 samples of manure, were taken from two defined locations (feeding area and resting area) in every pen for all trial stages (BT, AT, and ET). Manure samples were taken with a plastic cup ( $6 \mathrm{~cm}$ in diameter) which removed the whole litter material at these locations right down to the floor. All samples were immediately transferred to the laboratory for following analyses.

\subsection{Bacteriological Analyses and E. coli Isolation}

The bacteriological investigations were carried out as previously described [25]. In brief: Cloacal swab samples were directly streaked on Gassner agar plates, following an incubation overnight at $37^{\circ} \mathrm{C}$. For manure samples $50 \mathrm{~mL}$ of peptone water (Oxoid, Wesel, Germany) as well as the manure sample itself (25 g each) were put into a sterile Whirl-Pak ${ }^{\circledR}$ Bag (Nasco, Fort Atkinson, WI, USA). Bags were mixed for three minutes with a Bag Mixer ${ }^{\circledR} 400 \mathrm{VW}$ (Interscience, Saint Nom, France). Using a sterile loop, $10 \mu \mathrm{L}$ of each mixed-sample was streaked on Gassner agar (Oxoid, Wesel, Germany) and incubated at $37^{\circ} \mathrm{C}$ for $18-24 \mathrm{~h}$.

One single blue color colony from each plate was selected and spread onto Columbia blood agar (Oxoid, Wesel, Germany) and Tryptone Bile X-glucuronide (TBX) agar (Oxoid, Wesel, Germany). Incubation was done overnight at $37^{\circ} \mathrm{C}$. Bluegreen colonies on TBX agar detected glucuronidase activity. The positive indole test with Kovac's indole reagent (Merck, Darmstadt, Germany) was used to confirm the diagnosis.

\subsection{Antibacterial Susceptibility Testing}

The guidelines of the Clinical and Laboratory Standards Institute (CLSI) and the manufacturer's recommendations were the basis for testing the resistance of $E$. coli isolates using the broth microdilution technique. Micronaut plates (Merlin, Bornheim-Hersel, Germany) with Mueller-Hinton Broth (Merlin, Bornheim-Hersel, Germany) were used to determine minimal inhibitory concentrations 
(MICs) of enrofloxacin (ENR) and ampicillin (AMP). Dried antibacterial agents in serial dilutions of enrofloxacin and ampicillin were placed in wells of these plates, as previously described by Chuppava et al. [25]. MIC values were determined by visually reading and interpreting the results. As the reference strain, E. coli ATCC 25922 was tested concurrently on each testing day.

\subsection{Screening of Antibacterial Agents in Water Using High Performance Liquid Chromatography}

An aliquot of collected water samples with enrofloxacin from days ten to 14 and days 26 to 30 was used for analyses. The concentration of enrofloxacin in the water was determined using high performance liquid chromatography (HPLC) via the method described by Scherz [27]. Exactly $100 \mu \mathrm{L}$ of the sample was injected into the system with an autosampler (System Gold 508, Beckmann, Munich, Germany). A flow of $1 \mathrm{~mL}$ per minute was maintained by the System Gold 126 solvent module (Beckmann, Munich, Germany). A CC250/4 NUCLEODUR 100-5C 18ec (25 cm, Macherey-Nagel, Oensingen, Germany) column was used, this being connected to a precolumn (LiChroCART ${ }^{\circledR} 4-4$, Li- Chrospher ${ }^{\circledR} 100$ RP-18e, $5 \mu \mathrm{m}$, Merck, Darmstadt, Germany). A fluorescence detector (RF-551 Shimadzu, Nakagyo-ku, Japan) with $280 \mathrm{~nm}$ for excitation and $450 \mathrm{~nm}$ for emission was used for detection. The mobile phase consisted of $85 \%$ citrate buffer $\mathrm{pH} 3.0$ (citric acid monohydrate: $1.80 \mathrm{~g} / \mathrm{L}$ tri-sodium-citrate-dihydrate: $0.43 \mathrm{~g} / \mathrm{L}$ ). The concentration of enrofloxacin in the water samples was calculated with the external standard method.

\subsection{Statistical Analyses}

The data of resistance to antibacterial agents were performed using the SAS statistical software package version 7.1 (SAS Inst., Cary, NC, USA). MICs were summarized and reported as susceptible (S), intermediate (I), and resistant (R; the results were classified as $1=\mathrm{S}, 2=\mathrm{I}$, or $3=\mathrm{R}$ ), where CLSI veterinary breakpoints were available [28]. The analyses were made with these values for the categories. There are no intermediate values between classes one, two, and three. Therefore, a generally high standard deviation has to be tolerated. In the case of completely sensitive isolates at the beginning of the tests, the values are constant at one, i.e. the standard deviation is zero and can therefore not be seen graphically. Significant differences in the means of the resistance results between the four groups of flooring designs were tested using the repeated measures ANOVA (Fisher's Least Significant Difference (LSD)). This test was also used to determine the differences between the sampling stages and the frequency of resistance between the three trials.

\section{Results}

In total, $864 \mathrm{E}$. coli were isolated and analyzed. These isolates were obtained from 648 cloacal swabs and 216 manure samples at the BT, AT, and ET stages. In the water collected at days ten to 14 and days 26 to 30 in trial 2, the enrofloxacin concentration were 50.17 and $50.62 \mu \mathrm{g} / \mathrm{mL}$, respectively; in trial 3, water contained 49.87 and $50.42 \mu$ g enrofloxacin/mL, respectively.

\subsection{Differences in Resistance to Antibacterial Agents in E. coli between Sampling Points as Well as between Trials}

Enrofloxacin-resistant E. coli isolated from cloacal swabs and manure samples were found at the beginning of trial 1 (T1) and showed significantly higher mean resistance rates than in the other trials (Table 1). In contrast, in trials 2 (T2) and 3 (T3), none of the E. coli isolates during the BT stage were resistant to enrofloxacin. There were no significant differences between trial 2 and trial 3 during this stage.

Significant differences could be found between the trials during the AT and ET stages (Table 1). Isolates from the cloacal swabs and manure samples from trial 2 showed the significantly highest resistance to enrofloxacin of the isolates after administering Baytril ${ }^{\circledR}$, followed by mean values of trial 1 and trial 3 (cloacal swabs: 2.90, 1.98, and 1.00, respectively; manure samples: 2.63, 2.00, and 1.08, respectively; Table 1). Also, at the ET stage, the results of mean enrofloxacin resistance in trial 2 showed the same relationship to the other experiments (Table 1). 
Table 1. Means of enrofloxacin-resistant E. coli isolates from cloacal swab and manure samples from turkeys.

\begin{tabular}{|c|c|c|c|c|c|c|}
\hline \multirow{3}{*}{ Time of Sample Collection ** } & \multicolumn{6}{|c|}{ Enrofloxacin * } \\
\hline & \multicolumn{3}{|c|}{ Cloacal Swab $(N=648) * * *$} & \multicolumn{3}{|c|}{ Manure $(\mathrm{N}=216) * * *$} \\
\hline & BT & AT & ET & BT & AT & ET \\
\hline $\mathrm{T} 1$ & $1.42^{\mathrm{A}, \mathrm{b}}$ & $1.98^{\mathrm{B}, \mathrm{a}}$ & $2.20^{\mathrm{B}, \mathrm{a}}$ & $1.75^{\mathrm{A}, \mathrm{a}}$ & $2.00^{\mathrm{B}, \mathrm{a}}$ & $1.67^{\mathrm{B}, \mathrm{a}}$ \\
\hline $\mathrm{T} 2$ & $1.00^{\mathrm{B}, \mathrm{b}}$ & $2.90^{\mathrm{A}, \mathrm{a}}$ & $2.99 \mathrm{~A}, \mathrm{a}$ & $1.00^{\mathrm{B}, \mathrm{b}}$ & $2.63^{A, a}$ & $2.92^{\mathrm{A}, \mathrm{a}}$ \\
\hline $\mathrm{T} 3$ & $1.00^{\mathrm{B}, \mathrm{a}}$ & $1.00^{\mathrm{C}, \mathrm{a}}$ & $1.04^{\mathrm{C}, \mathrm{a}}$ & $1.00^{\mathrm{B}, \mathrm{a}}$ & $1.08^{\mathrm{C}, \mathrm{a}}$ & $1.00^{\mathrm{C}, \mathrm{a}}$ \\
\hline
\end{tabular}

$\mathrm{A}, \mathrm{B}, \mathrm{C}$ means in the same column differ significantly between the experiments $(p<0.05) ;{ }^{\mathrm{a}, \mathrm{b}}$ means differ significantly between the stage of sampling within one experiment $(p<0.05) ;{ }^{*}$ MICs were summarized and reported as susceptible $(\mathrm{S})$, intermediate $(\mathrm{I})$, and resistant $(\mathrm{R})$. Afterwards the results were classified as $1=\mathrm{S}, 2=\mathrm{I}$, or $3=\mathrm{R}$ and means thereof were calculated; ${ }^{* *} \mathrm{BT}=$ before treatment; $\mathrm{AT}=$ after treatment; $\mathrm{ET}=$ end of trial. $\mathrm{T} 1=$ untreated antibiotic trial, T2 $=$ treated antibiotic trial, $\mathrm{T} 3=$ trial with simulated water spillage containing antibiotic; ${ }^{* * *}$ Cloacal swabs: $\mathrm{N}=648$; per trial BT: $\mathrm{n}=24$, AT: $\mathrm{n}=96$, ET: $\mathrm{n}=96$; poultry manure: $\mathrm{N}=216$; per trial BT: $\mathrm{n}=24, \mathrm{AT}: \mathrm{n}=24$, ET: $n=24$. G1 = entire floor pen covered with litter; $\mathrm{G} 2=$ floor pen covered with litter and having floor heating; G3 = partially (50:50) slatted flooring including an area that was littered; G4 = fully slatted flooring with a sand bath $\left(900 \mathrm{~cm}^{2}\right)$.

When comparing the sampling stages (Table 1), the means in enrofloxacin resistance were significantly different between trial 1 and trial 2 regarding the $E$. coli isolated from the cloacal swabs (Table 1). For the medicated group (T2), the number of samples with isolation of resistant E. coli in materials (cloacal swab and manure sample) significantly increased from the BT to AT stages upon exposure to enrofloxacin. Nevertheless, the E. coli from all samples showed no significant differences in the resistance between the AT and ET stages (Table 1).

The results of means in resistance of ampicillin resistant E. coli isolates in trials 1, 2, and 3 are presented in Table 2. E. coli isolates from cloacal swabs were $100 \%$ susceptible to ampicillin during the BT stage except in trial 1 . In this trial, isolates showed a significantly higher resistance to ampicillin $(\mathrm{G} 1=1.33, \mathrm{G} 2=1.00, \mathrm{G} 3=1.00$, respectively; Table 2).

Table 2. Means of ampicillin-resistant E. coli isolates from cloacal swab and litter/excreta samples from turkeys.

\begin{tabular}{|c|c|c|c|c|c|c|}
\hline \multirow{3}{*}{ Time of Sample Collection ** } & \multicolumn{6}{|c|}{ Ampicillin * } \\
\hline & \multicolumn{3}{|c|}{ Cloacal Swab $(\mathrm{N}=648) * * *$} & \multicolumn{3}{|c|}{ Manure $(\mathrm{N}=216) * * *$} \\
\hline & BT & AT & ET & BT & AT & ET \\
\hline $\mathrm{T} 1$ & $1.33^{\mathrm{A}, \mathrm{a}}$ & $1.80^{\mathrm{B}, \mathrm{a}}$ & $1.52^{\mathrm{B}, \mathrm{a}}$ & $1.42^{\mathrm{A}, \mathrm{a}}$ & $1.33^{\mathrm{B}, \mathrm{a}}$ & $1.00^{\mathrm{B}, \mathrm{a}}$ \\
\hline $\mathrm{T} 2$ & $1.00^{\mathrm{B}, \mathrm{b}}$ & $1.31^{\mathrm{C}, \mathrm{a}}$ & $2.00 \mathrm{~A}, \mathrm{a}$ & $1.00^{\mathrm{B}, \mathrm{b}}$ & $2.13^{\mathrm{A}, \mathrm{a}}$ & $1.67^{\mathrm{A}, \mathrm{a}}$ \\
\hline $\mathrm{T} 3$ & $1.00^{\mathrm{B}, \mathrm{b}}$ & $2.08^{\mathrm{A}, \mathrm{a}}$ & $1.73^{\mathrm{B}, \mathrm{a}}$ & $1.25 \mathrm{AB}, \mathrm{a}$ & $1.17^{\mathrm{B}, \mathrm{a}}$ & $1.83^{\mathrm{A}, \mathrm{a}}$ \\
\hline
\end{tabular}

A, B, C means in the same column differ significantly between the experiments $(p<0.05)$; ${ }^{\text {a b }}$ means differ significantly between the stage of sampling within one experiment $(p<0.05) ;{ }^{*}$ MICs were summarized and reported as susceptible $(\mathrm{S})$, intermediate $(\mathrm{I})$, and resistant $(\mathrm{R})$. Afterwards the results were classified as $1=\mathrm{S}, 2=\mathrm{I}$, or $3=\mathrm{R}$ and means thereof were calculated; ${ }^{* *} \mathrm{BT}=$ before treatment; $\mathrm{AT}=$ after treatment; $\mathrm{ET}=$ end of trial. $\mathrm{T} 1=$ untreated antibiotic trial, $\mathrm{T} 2=$ treated antibiotic trial, $\mathrm{T} 3=$ trial with simulated water spillage containing antibiotic; ${ }^{* * *}$ Cloacal swabs: $\mathrm{N}=648$; per trial BT: $\mathrm{n}=24, \mathrm{AT}: \mathrm{n}=96$, ET: $\mathrm{n}=96$; poultry manure: $\mathrm{N}=216$; per trial BT: $\mathrm{n}=24, \mathrm{AT}: \mathrm{n}=24$, ET: $n=24 ; \mathrm{G} 1=$ entire floor pen covered with litter; G2 = floor pen covered with litter and having floor heating; G3 = partially (50:50) slatted flooring including an area that was littered; G4 = fully slatted flooring with a sand bath $\left(900 \mathrm{~cm}^{2}\right)$.

During the AT stage, a significant difference between the three trials occurred in isolates from the cloacal samples. At this point in time, isolates in T3 showed the significantly highest means in enrofloxacin resistance in cloacal swabs, whereas in manure samples, T2-samples had the highest means. During the ET stage in trial 2, the means of ampicillin-resistant E. coli isolates from cloacal swabs were significantly higher than in the other trials (Table 2). In manure samples, no more ampicillin resistance was found in $\mathrm{T} 1$ during the ET stage. 
The results of mean ampicillin resistance in T2 (animals treated twice with enrofloxacin) differed significantly between the sampling days regarding the E. coli strains isolated from the cloacal swabs and manure samples. There was a significant increase in means from the BT to the AT stage (Table 2). In trial 3, there was also a significant increase in means of resistance. The percentage of susceptible isolates changed from $100 \%$ susceptible isolates to $46 \%$ after simulation of water losses with water containing antibiotic. The significance between the AT and ET stages could not be found in all trials (Table 2).

\subsection{Testing the Effect of Different Flooring Designs on the Resistance to Antibacterial Agents in E. coli}

The mean values of resistance of $E$. coli isolates to enrofloxacin and ampicillin depending on sampling stage and flooring design are presented in Figures $2 \mathrm{a}-\mathrm{d}$ and $3 \mathrm{a}-\mathrm{d}$.
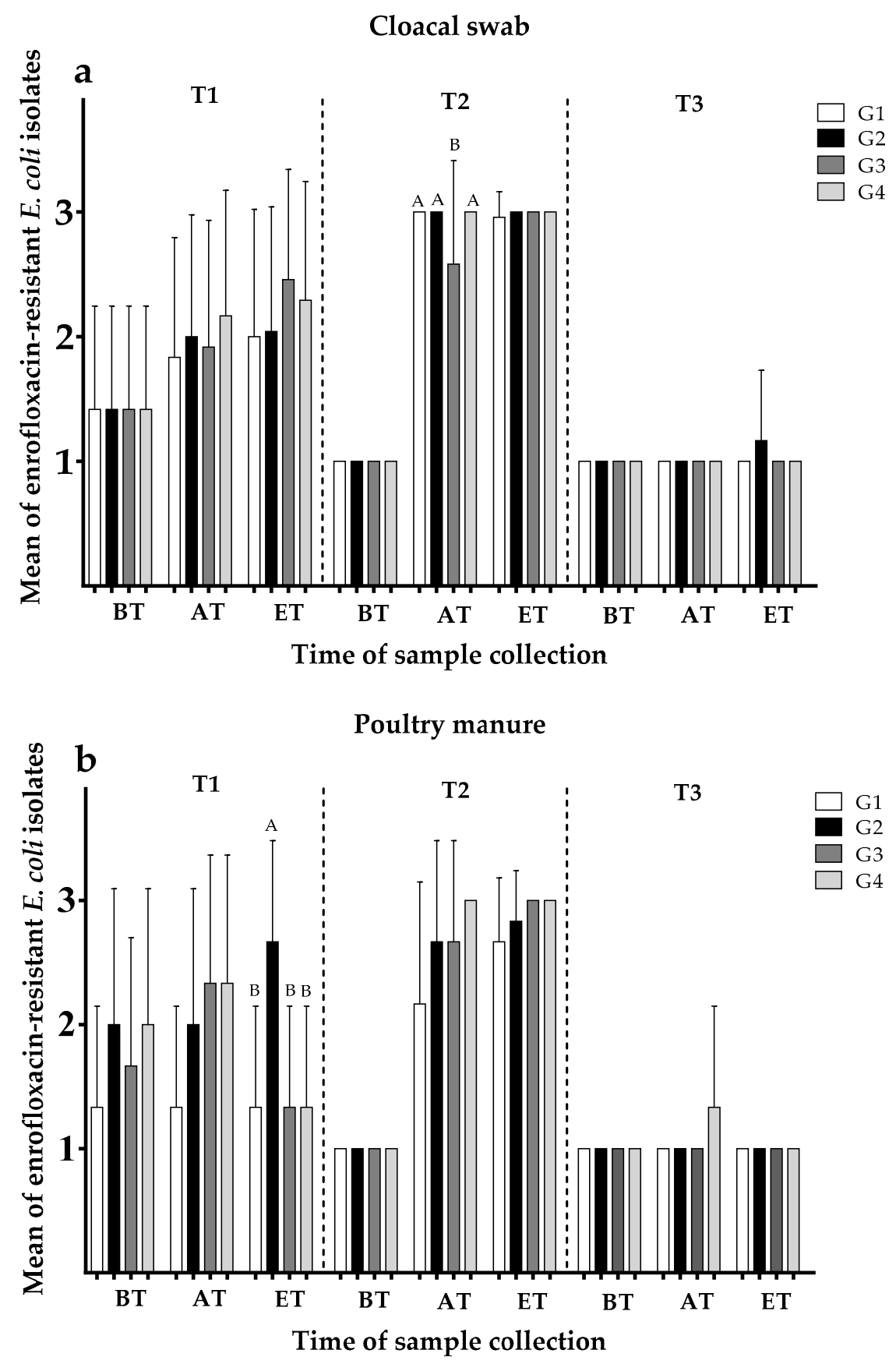

Figure 2. Cont. 

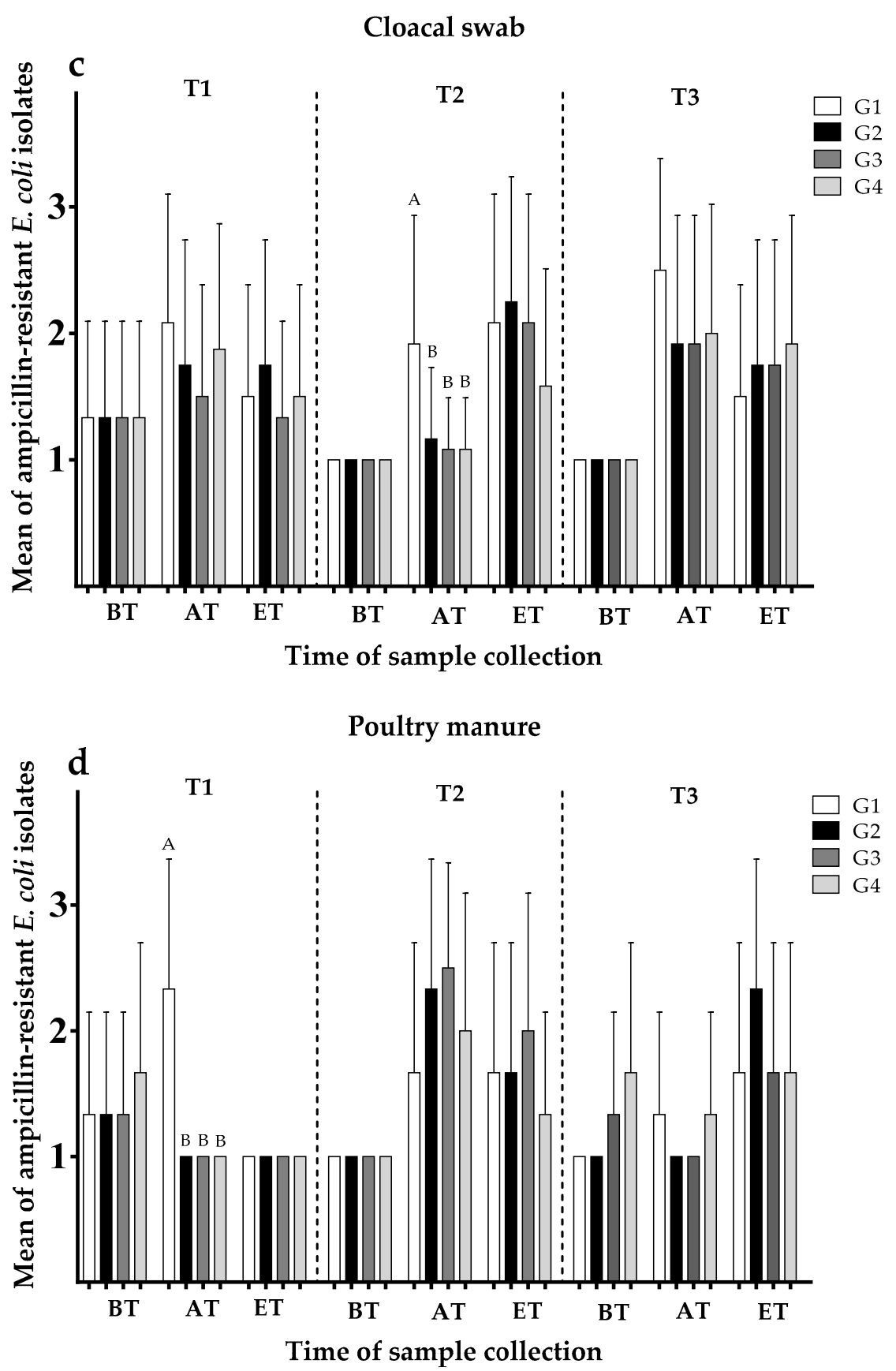

Figure 2. Means of susceptible (=1); intermediate (=2); and resistant (=3) E. coli isolates concerning enrofloxacin resistance in (a) cloacal swabs and (b) poultry manure samples as well as ampicillin resistance in (c) cloacal swabs and (d) poultry manure samples before treatment (BT), after treatment (AT) and the end of trial (ET; cloacal swabs: $\mathrm{N}=648$; per trial BT: $\mathrm{n}=24, \mathrm{AT}: \mathrm{n}=96, \mathrm{ET}: \mathrm{n}=96$; poultry manure: $\mathrm{N}=216$; per trial BT: $\mathrm{n}=24$, AT: $\mathrm{n}=24$, ET: $\mathrm{n}=24$ ). $\mathrm{T} 1=$ no treatment with antibiotic; $\mathrm{T} 2$ = treatment of enrofloxacin via drinking water; and T3 = water (containing enrofloxacin) loss simulation trial. G1 = entire floor pen covered with litter; G2 = floor pen covered with litter and having floor heating; G3 = partially (50:50) slatted flooring including an area that was littered; and G4 = fully slatted flooring with a sand bath $\left(900 \mathrm{~cm}^{2}\right)$. A, B means differ significantly between the groups at one sampling $(p<0.05)$. 


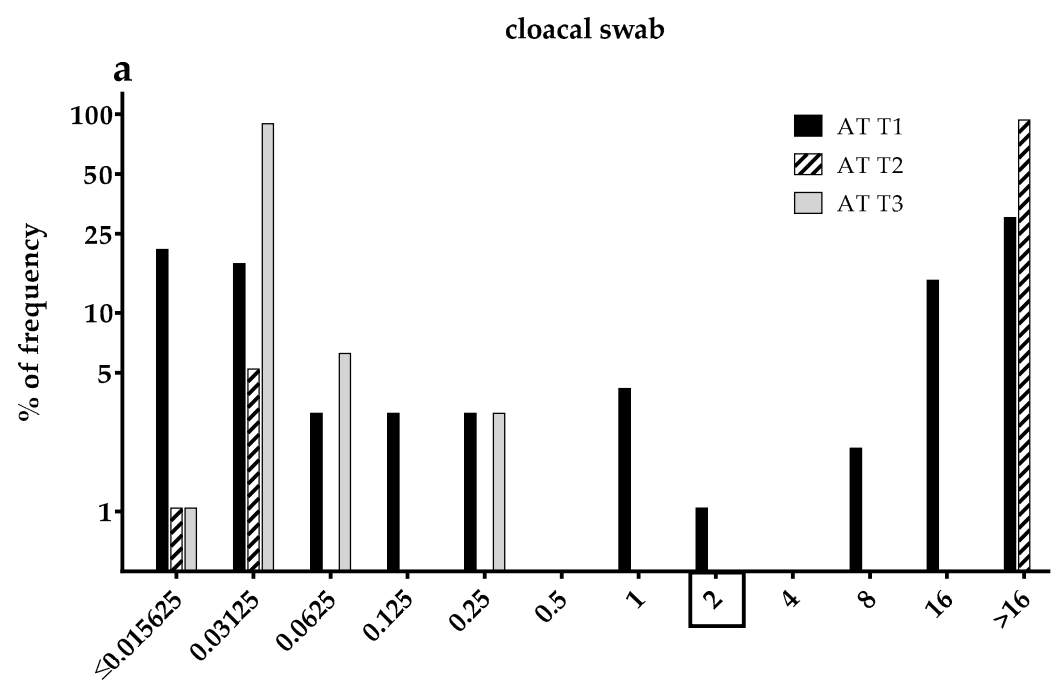

Enrofloxacin MIC distribution $(\mu \mathrm{g} / \mathrm{mL})$

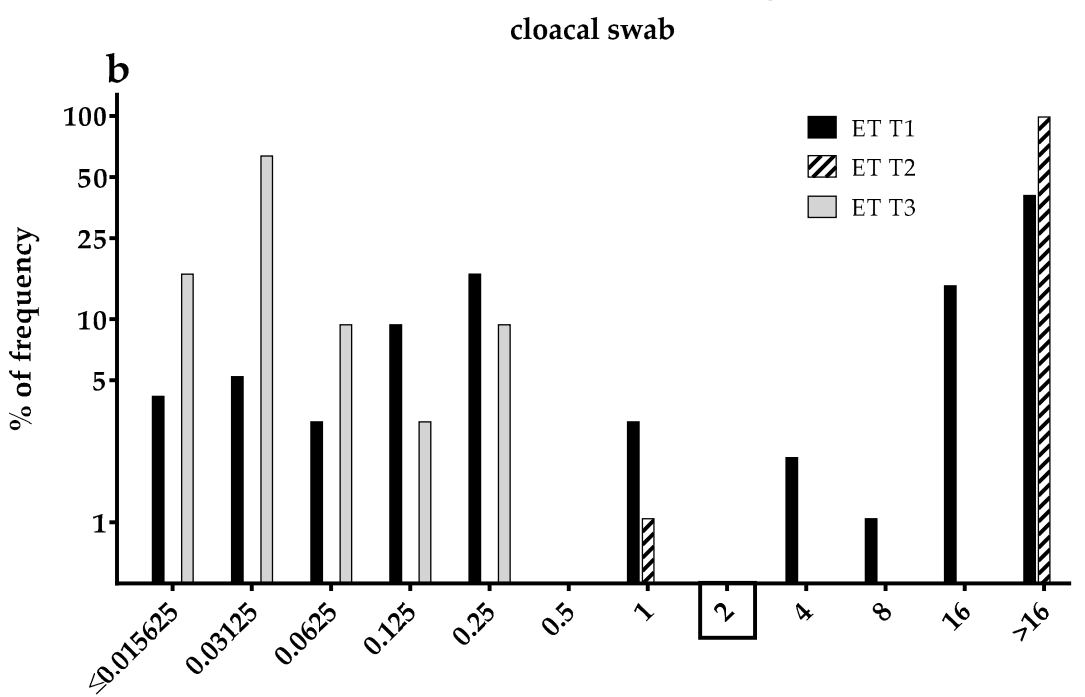

Enrofloxacin MIC distribution $(\mu \mathrm{g} / \mathrm{mL})$

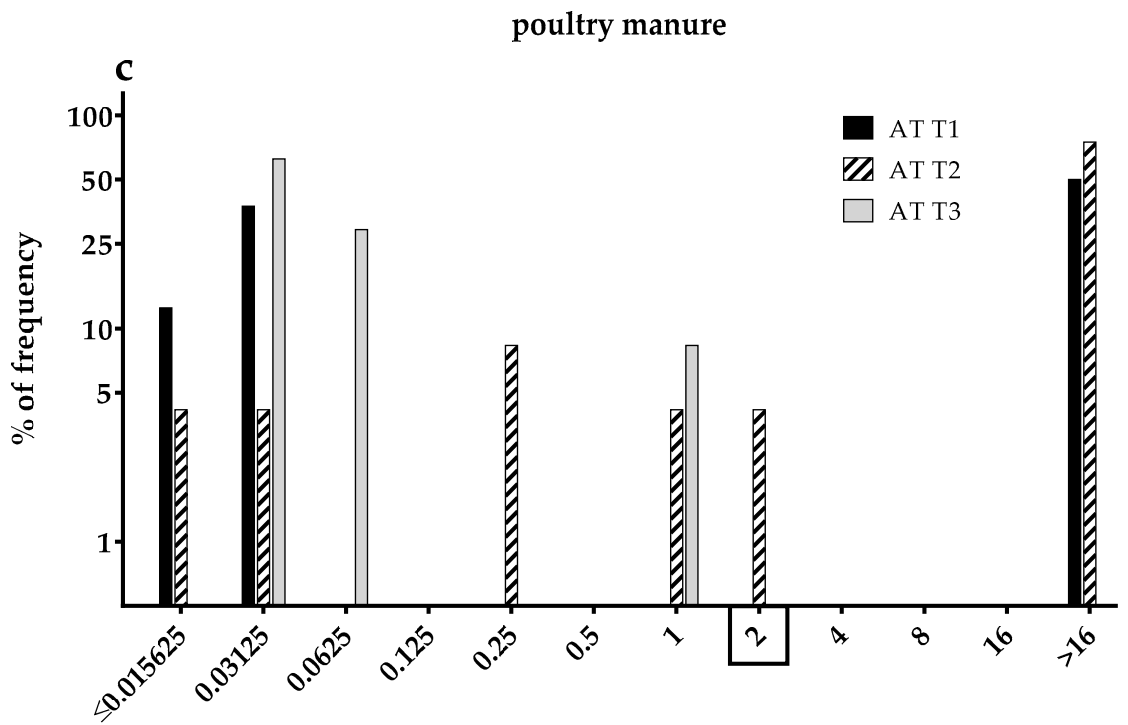

Enrofloxacin MIC distribution $(\mu \mathrm{g} / \mathrm{mL})$

Figure 3. Cont. 


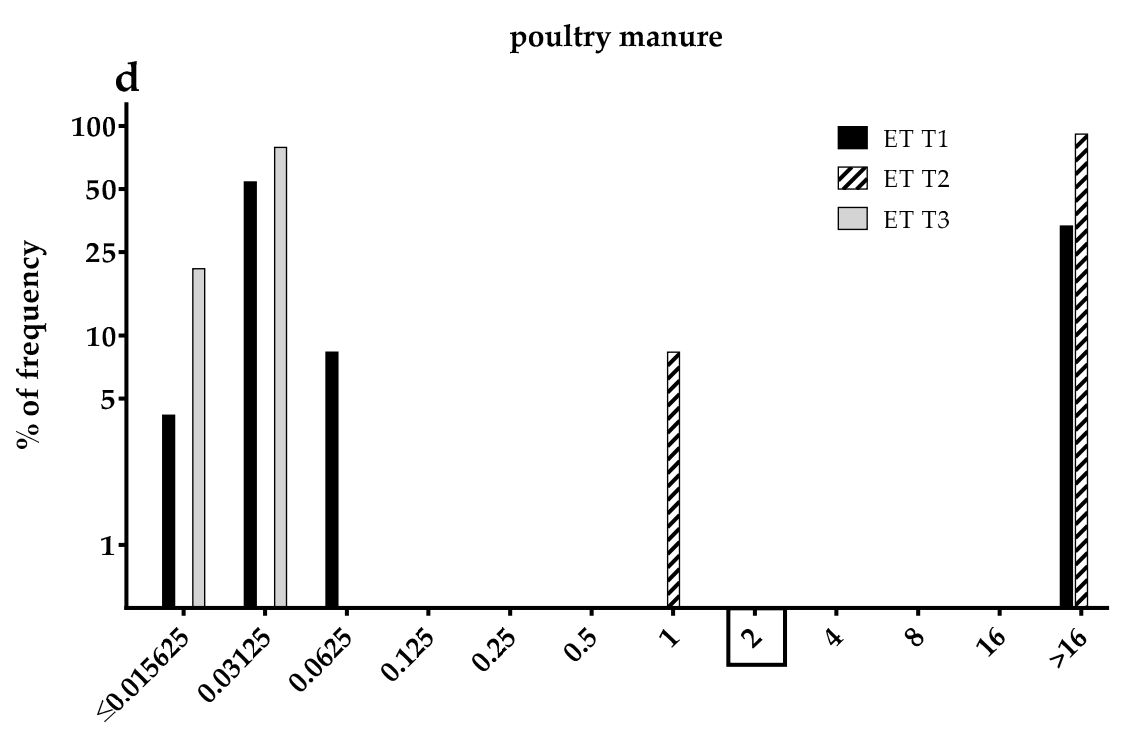

Enrofloxacin MIC distribution $(\mu \mathrm{g} / \mathrm{mL})$

Figure 3. Percentage of frequency of enrofloxacin minimum inhibitory concentration (MIC) distribution in commensal E. coli isolates from (a) cloacal swabs after treatment (AT) and (b) end of trial (ET) as well as in (c) poultry manure samples during AT and (d) ET of untreated antibiotic (T1), treated twice with enrofloxacin via drinking water (T2) and simulated water spillage with water containing enrofloxacin (T3) in turkeys (cloacal swabs: $\mathrm{N}=576$; per trial AT: $\mathrm{n}=96, \mathrm{ET}$ : $\mathrm{n}=96$; poultry manure samples: $\mathrm{N}=144$; per trial AT: $\mathrm{n}=24$, ET: $\mathrm{n}=24$ ). Rectangle on the $\mathrm{x}$-axis: Clinical Laboratory Standard Institute (CLSI) has determined a veterinary specific breakpoint of $\geq 2 \mu \mathrm{g} / \mathrm{mL}$ enrofloxacin for $E$. coli from chickens and turkeys.

\subsubsection{Development of Enrofloxacin Resistance Depending on Group}

Enrofloxacin resistance in E. coli isolates from all samples did not show any differences between the groups during the BT stage. During the AT stage in trial 2 (Figure 2a), E. coli isolated from cloacal swabs in G3 showed significantly lower means in resistance rates to enrofloxacin than the isolates collected from animals in other groups showing highest possible means (G3: 2.58; mean values of enrofloxacin resistance in E. coli for each group in detail in Supplementary Table S1a). During the ET stage in trial 1, G2 showed significantly higher means in resistance values of enrofloxacin in manure samples (Figure $2 \mathrm{~b}$ ). The E. coli isolates in T3 acquired from cloacal swabs and manure samples (Figure 2a,b) were susceptible to enrofloxacin and showed no significant differences between groups; $98 \%$ and $96 \%$, respectively.

\subsubsection{Development of Ampicillin Resistance Depending on Group}

Regarding ampicillin resistance in all trials (Figure 2c,d), there were no significant differences between the groups concerning resistance in isolates from cloacal swabs and manure samples during the BT stages. In contrast, E. coli isolates from cloacal swabs during the AT stage in trial 2 (Figure 2c) from G1 demonstrated higher resistance means than in the other groups (G1: 1.92; mean values of ampicillin resistance in E. coli for each group in detail in Supplementary Table S1b). In trial 2, the results of means of ampicillin resistance from the manure samples during the AT stage also showed higher values for G1 than observed in either G2, G3, or G4 $(2.33,1.00,1.00$, and 1.00, respectively; Figure 2d; mean values of ampicillin resistance in E. coli for each group in detail in Supplementary Table S2b). There was no difference in means of ampicillin-resistant $E$. coli isolated from cloacal swabs and manure samples during the ET stage in all trials (Figure 2c,d). 


\subsection{Enrofloxacin MICs Distributions of the Commensal E. coli Isolates}

The percentage of frequency of MICs distribution of the 576 commensal E. coli isolates from cloacal swabs and manure samples to enrofloxacin during the AT and ET stages are shown in Figure 3a-d. For E. coli from chickens and turkeys, the Clinical Laboratory Standard Institute (CLSI [28]) determined a veterinary specific breakpoint of $\geq 2 \mu \mathrm{g} / \mathrm{mL}$ for enrofloxacin.

When comparing the three trials (Figure 3a-d), a large number of resistant $E$. coli isolates during the AT and ET stages were found in trial 2, 93\% and 99\% in cloacal swabs, respectively (Figure 3a,b) and in manure samples, $79 \%$ and $92 \%$ during the AT and ET stages, respectively (Figure 3c,d). On the other hand, all E. coli isolates from trial 3 during the AT stage were susceptible to enrofloxacin $(\leq 0.25 \mu \mathrm{g} / \mathrm{mL})$.

Regarding the MICs distribution for enrofloxacin, susceptible isolates from cloacal swabs in trial 1 decreased gradually from $52 \%$ during the AT stage to $42 \%$ at the end of the study (Figure $3 a, b$ ). In contrast, the percentage of resistant E. coli isolated in trial 2 slightly increased from $93 \%$ to $99 \%$ during the AT and ET stages, respectively (Figure 3a,b). On the other hand, nearly all of the E. coli isolates from the cloacal swabs and manure samples in trial 3 had enrofloxacin MIC-values below the clinical breakpoint (MIC $\leq 2 \mu \mathrm{g} / \mathrm{mL}$ ).

\section{Discussion}

The antibacterial agents used in the poultry for treatment or prophylaxis are implicated for the development of bacterial resistance [29]. Treatment in large groups of chickens is often done by oral administration [30]. Some studies reported that antibacterial agents or their metabolites are excreted in manure and residue can therefore be found in the environment $[16,31,32]$.

\subsection{Consequences of the Oral Administration of Antibacterial Agents}

In the present study, one week after the first administration period (d21; AT stage), the amount of resistance was higher compared to the E. coli isolates before treatment. A higher rate of enrofloxacin-resistant $E$. coli after oral administration of antibacterial agents was observed in several studies $[25,33,34]$. Chuppava et al. [25] stated that a single treatment for five days with enrofloxacin led to markedly reduced ratios of susceptible $E$. coli isolates in cloacal swabs and manure samples. The highest proportion of cloacal swabs with resistant $E$. coli was found directly after treatment. Afterwards, a decrease in resistance to enroflaxacin was seen. Therefore, our results are in agreement with those of Chuppava et al. [25] who described a very rapid occurrence of FQ resistance among the commensal E. coli after enrofloxacin treatment in poultry. Nevertheless, no difference in resistance in E. coli isolates was found between the AT and ET stages after two consecutive treatments with enrofloxacin in this study because MIC values were already very high after one-time treatment.

As expected, after treatment with enrofloxacin, increased MIC values above $2 \mu \mathrm{g} / \mathrm{mL}$ occurred in E. coli isolates (T2) with high detection rates up to the end of the trial. Scherz et al. [27] showed that a long-term exposure ( 21 days) of the commensal flora of poultry to enrofloxacin leads to an amplification and selection of resistant $-E$. coli isolates. These isolates persist in the commensal microbiota. The transmission of $E$. coli isolates of animal origin between the animals in the same pen as well as into the environment may contribute directly to the spread of resistant bacteria in general and may also be a problem for public health [35].

Medication is the main reason for occurrence of resistance to antibacterial agents in E. coli [31]. Oral group treatments led to an environmental contamination with antibacterial agents. The application procedure itself or excreted feces from treated animals can be the source [36]. Due to the fact that the metabolic rate of antibiotics is low, $90 \%$ of the administered dose is excreted via feces [5]. Avian intestines can act as potential reservoirs of E. coli [37]. Thus, there is a higher risk for resistance to antibacterial agents spreading from birds to other birds or from birds to the environment. In other European countries, the higher occurrence of FQ resistance in broilers compared to turkeys has been 
suggested to depend on an overall use-dependent higher exposure to FQ [3]. It should be noted, however, that the fattening period in turkeys takes much longer under field conditions. Therefore, the resistance situation in the present investigations at the end of the experiment is not comparable with the resistance situation occurring within the normal fattening duration.

In agreement with our data, Jurado et al. [34] and Chuppava et al. [25] found a significant increase in the frequency of resistance to ampicillin in $E$. coli isolates from poultry after orally administering enrofloxacin. These findings may be due to the coselection of $\beta$-lactam resistance genes. As the transmissible genetic elements were not analyzed in our study, further studies are recommended in order to confirm the role of such elements in the spread of resistance genes in poultry for E. coli.

\subsection{Effects of the Development of Resistance to Antibacterial Agents in E. coli by Water Loss Simulation (Indirect Administration)}

To the best of our knowledge, using water loss simulations by spraying the water containing enrofloxacin exclusively into the litter or onto the slatted flooring in the drinking area in order to study the development of resistance to antibacterial agents has not been previously reported. In this study, it was hypothesized that excreted or metabolized enrofloxacin might alone influence the occurrence of resistance to antibacterial agents. However, in the present study, we could not verify the occurrence of enrofloxacin resistance due to spraying water with enrofloxacin directly into the animals' environment.

Earlier reports suggested that the carry-over effect of antibacterial agents like FQ as well as their active metabolites in the stable could foster the development of antibacterial resistance via oral ingestion by animals [27]. However, in the present investigation, we sprayed enrofloxacin containing water directly into the environment. In contrast, in the aforementioned study, subtherapeutic dosages ( $3 \%$ and $10 \%$ of the recommended dosage of $10 \mathrm{mg} / \mathrm{kg}$ body weight) were directly applied to drinking water for 21 days, which could explain the difference. The active dose may therefore have been significantly lower in our own experiments.

Chuppava et al. [25] stated from their experimental model that removing the animals from contaminated pens after antibiotic treatment might be the reason for the lower percentage of resistant E. coli isolates in the observed animals. Changing the environment was assumed to lead to a lower percentage of resistant $E$. coli isolates in manure. A lower exposure to resistant bacteria in manure as well as antibacterial agent residues was discussed as the cause for this observation. Additionally, in poultry, dirty or contaminated litter and other animal management parameters affect the microbial composition of the chicken gastrointestinal tract. This influence can be either directly, by providing a continuous source of bacteria, or indirectly, by influencing the physical condition and defence of the birds [37].

\subsection{Effect of Different Types of Flooring Design on the Development of Resistant E. coli}

Up to now, little is known about reducing the development of resistance to antibacterial agents by using different flooring designs simulating varying contact intensity between animals and manure. The development of enrofloxacin and ampicillin resistance in E. coli was almost independent of flooring design in the present study. Differences in antibacterial susceptibility of commensal E. coli isolates from turkeys depending on flooring design have been previously reported [25]. Chuppava et al. [25] mentioned that flooring design had hardly any effect on the development of resistance against antibacterial agents. Nevertheless, in fully slatted flooring systems, with animals having no contact to their litter, resistance to antibacterial agents still develops in the animals.

In $\mathrm{T} 1$, overall, the group with floor heating (G2; average floor temperature in all trials: $\mathrm{G} 1=27.0 / \mathrm{G} 2=30.5 / \mathrm{G} 3=26.5 / \mathrm{G} 4=26.0^{\circ} \mathrm{C}$ ) showed a significantly higher number of resistant $E$. coli isolates than the other groups. Previous studies showed that the resistance to antibacterial agents in animals can change when they are kept in a heat stress environment [25,38]. A high amount of enrofloxacin resistant isolates from cloacal swabs in fattening turkeys was already reported by Chuppava et al. [25] in a group with floor heating. Also, in swine, Moro et al. [38] found a significant 
increase in resistant $E$. coli isolates in the intestinal flora after the animals had been exposed to heat stress (environmental temperature: $34^{\circ} \mathrm{C}$ ).

A significantly higher prevalence of ampicillin resistance in $E$. coli isolates from excreta material from cloacal swabs and manure samples was found in the entire floor pen with litter (G1) even when no ampicillin had been administered to the animals and the pens and the stable had been tested and found to be free of Enterobacteriaceae at the start of the trial. Further genetic analyses were not conducted. Therefore, the reason for this difference remains unknown.

\subsection{Natural Resistance to Antibacterial Agents Found in Day-Old Chickens}

Turkey poults in this study had not been previously exposed to antibacterial agents. However, E. coli was isolated from day-old chicks' meconium in trial 1. Isolates showed resistance to enrofloxacin $(48 \%)$ and ampicillin $(42 \%)$. Similar results were reported in previous studies that found one-day-old chicks to be E. coli resistant to enrofloxacin [39] and 100\% resistant to ampicillin [25]. It has to be mentioned that also other research groups observed high rates of resistance to antibacterial agents already before treatment as well as in the absence of treatment [40]. A vertical transmission of resistant isolates along the production pyramid can occur [3,41]. Also, contamination in the hatchery environment is possible [42]. Persoons et al. [43] stated that besides management, also hatchery-related factors can influence the occurrence of resistance to antibacterial agents. In newly hatched chicks, the common bacteria in the environment, whether antibacterial susceptible or resistant, colonize the intestines and become part of the intestinal normal microflora. Thus, contamination of chickens via vertical transmission could be a possible explanation for the resistance rates found in our study.

The natural enrofloxacin resistance observed in this present study increased strongly. This increase was higher than after one time treatment, as previously reported [25], despite the absence of antibacterial agent usage (T1). Chuppava et al. [25] suggested, according to their findings, that resistance could be reduced or increased, but not eliminated from the animals even with strict disinfection procedures during the experiment. From literature, it is known that a large number of animals carry resistant E. coli. These animals can shed huge numbers of resistant organisms. This could result in a rapid contamination of the other individuals in the same pen and in the stable environment [41]. Resistant bacteria can be ingested by birds from the environment. After entering their gut, these may cause the development of resistant E. coli. However, there are several possible mechanisms responsible for the development of quinolone resistance [44].

Therefore, further research is strongly recommended to analyze the genetic basis of resistance in the isolates in order to understand the resistance mechanism's origin, development and transfer.

\section{Conclusions}

In this study, resistance to enrofloxacin was detected at a very high frequency after treatments with enrofloxacin via drinking water. Therefore, the oral administration of enrofloxacin seems to be associated with a significant increase in the frequency of resistance to enrofloxacin in commensal E. coli isolates from turkeys. In addition, prevalence of isolates resistant to ampicillin rose significantly. Resistance to enrofloxacin was not detected when the antibacterial agent substance was indirectly sprayed with water into the environment of fattening turkeys. Flooring structure designs did not directly affect the development of resistance to antibacterial agents, or in groups where the animals had no contact to litter. The existence of resistant $E$. coli isolates in one-day-old birds strongly suggests vertical transmission from parent flocks as one possible explanation.

Furthermore, our results can provide useful information, prompting further studies on quinolone resistance mechanisms in commensal E. coli depending on different housing systems. However, we cannot consider all interactions when only one isolate is taken from a sample and then, by way of example, we try to deduce the complexity of the development of resistance. Therefore, research is needed to further investigate possible explanations regarding the mechanism behind the dissemination of enrofloxacin-resistant $E$. coli in fattening turkeys. 
Supplementary Materials: The following are available online at http:/ /www.mdpi.com/1660-4601/15/9/1993/ s1, Table S1a: Means of enrofloxacin- resistant E. coli isolates from cloacal swab and manure samples from turkeys, Table S1b: Means of ampicillin-resistant E. coli isolates from cloacal swab and manure samples from turkeys.

Author Contributions: Conceptualization, C.V. and M.K.; Methodology, B.K., J.M., M.K. and C.V.; Validation, B.C., C.V., B.K. and J.M.; Formal Analysis, B.C., B.K., and C.V.; Investigation, B.C., C.V., A.A.E.-W. and J.M.; Resources, C.V. and M.K.; Data Curation, B.C. and C.V.; Writing-Original Draft Preparation, B.C. and C.V.; Writing-Review \& Editing, B.C., C.V., B.K., A.A.E.-W., J.M. and M.K.; Visualization, B.C. and C.V.; Supervision, C.V.; Project Administration, C.V. and B.K.; Funding Acquisition, C.V. and M.K.

Funding: This project was supported by funds of the Federal Ministry of Food and Agriculture (BMEL, Germany) based on a decision of the Parliament of the Federal Republic of Germany via the Federal Office for Agriculture and Food (BLE, Germany) under the innovation support program. This publication was supported by the Deutsche Forschungsgemeinschaft and University of Veterinary Medicine Hannover, Foundation, Germany within the funding program Open Access Publishing.

Acknowledgments: We would like to thank Frances Sherwood-Brock for proof-reading the manuscript to ensure correct English.

Conflicts of Interest: The authors declare no conflicts of interest.

\section{References}

1. Kaesbohrer, A.; Schroeter, A.; Tenhagen, B.A.; Alt, K.; Guerra, B.; Appel, B. Emerging antimicrobial resistance in commensal Escherichia coli with public health relevance. Zoonoses Public Health 2012, 59, 158-165. [CrossRef] [PubMed]

2. Schroeter, A.; Kaesbohrer, A. German Antimicrobial Resistance Situation in the Food Chain-DARlink; Bundesinstitut fur Risikobewertung (BfR): Berlin, Germany, 2010; pp. 127-133.

3. ECDC; EFSA; EMA. Second joint report on the integrated analysis of the consumption of antimicrobial agents and occurrence of antimicrobial resistance in bacteria from humans and food-producing animals-joint interagency antimicrobial consumption and resistance analysis (JIACRA) report. EFSA J. 2017, 15, 4872.

4. WHO. Antimicrobial Resistance: Global Report on Surveillance. World Health Organization, 2014. Available online: http://apps.who.int/iris/bitstream/10665/112642/1/9789241564748_eng.pdf (accessed on 29 March 2018).

5. Kumar, K.; Gupta, S.C.; Chander, Y.; Singh, A.K. Antibiotic use in agriculture and its impact on the terrestrial environment. Adv. Agron. 2005, 87, 1-54.

6. Janusch, F.; Scherz, G.; Mohring, S.A.; Hamscher, G. Determination of fluoroquinolones in chicken feces-A new liquid-liquid extraction method combined with LC-MS/MS. Environ. Toxicol. Pharmacol. 2014, 38, 792-799. [CrossRef] [PubMed]

7. Riaz, L.; Mahmood, T.; Khalid, A.; Rashid, A.; Siddique, M.B.A.; Kamal, A.; Coyne, M.S. Fluoroquinolones (FQs) in the environment: A review on their abundance, sorption and toxicity in soil. Chemosphere 2018, 191, 704-720. [CrossRef] [PubMed]

8. Tacconelli, E.; Sifakis, F.; Harbarth, S.; Schrijver, R.; van Mourik, M.; Voss, A.; Sharland, M.; Rajendran, N.B.; Rodríguez-Baño, J.; Bielicki, J. Surveillance for control of antimicrobial resistance. Lancet Infect. Dis. 2017, 18, E99-E106. [CrossRef]

9. Projahn, M.; Daehre, K.; Semmler, T.; Guenther, S.; Roesler, U.; Friese, A. Environmental adaptation and vertical dissemination of esbl-/pampc-producing Escherichia coli in an integrated broiler production chain in the absence of an antibiotic treatment. Microb. Biotechnol. 2018, 11, 1-10. [CrossRef] [PubMed]

10. Varga, C.; Rajić, A.; McFall, M.E.; Reid-Smith, R.J.; Deckert, A.E.; Pearl, D.L.; Avery, B.P.; Checkley, S.L.; McEwen, S.A. Comparison of antimicrobial resistance in generic Escherichia coli and Salmonella spp. Cultured from identical fecal samples in finishing swine. Can. J. Vet. Res. 2008, 72, 181-187. [PubMed]

11. EFSA. The European Union summary report on antimicrobial resistance in zoonotic and indicator bacteria from humans, animals and food in 2013. EFSA J. 2015, 13, 4036.

12. ECDC; EFSA; EMA. First joint report on the integrated analysis of the consumption of antimicrobial agents and occurrence of antimicrobial resistance in bacteria from humans and food-producing animals. EFSA J. 2015, 13, 4006. 
13. European Surveillance of Veterinary Antimicrobial Consumption (ESVAC). Sales of Veterinary Antimicrobial Agents in 30 European Countries in 2015. 2017. Available online: https://publications.europa.eu/ en/publication-detail/-/publication/7656bd79-d970-11e7-a506-01aa75ed71a1/language-en (accessed on 29 March 2018).

14. GERMAP. Report on the Consumption of Antimicrobials and the Spread of Antimicrobial Resistance in Human and Veterinary Medicine in Germany; Antiinfectives Intelligence: Rheinbach, Germany, 2016.

15. Kreienbrock, L. Ergebnisse aus VetCAb, Antibiotikaresistenz in der Lebensmittelkette; Bundesinstitut für Risikobewertung (BfR): Berlin, Germany, 2013; pp. 52-54.

16. Diarra, M.S.; Malouin, F. Antibiotics in Canadian poultry productions and anticipated alternatives. Front. Microbiol. 2014, 5, 282. [CrossRef] [PubMed]

17. Furtula, V.; Farrell, E.; Diarrassouba, F.; Rempel, H.; Pritchard, J.; Diarra, M. Veterinary pharmaceuticals and antibiotic resistance of Escherichia coli isolates in poultry litter from commercial farms and controlled feeding trials. Poult. Sci. 2010, 89, 180-188. [CrossRef] [PubMed]

18. Dandachi, I.; Sokhn, E.S.; Dahdouh, E.A.; Azar, E.; El-Bazzal, B.; Rolain, J.-M.; Daoud, Z. Prevalence and characterization of multi-drug-resistant gram-negative bacilli isolated from Lebanese poultry: A nationwide study. Front. Microbiol. 2018, 9, 550. [CrossRef] [PubMed]

19. Chantziaras, I.; Boyen, F.; Callens, B.; Dewulf, J. Correlation between veterinary antimicrobial use and antimicrobial resistance in food-producing animals: A report on seven countries. J. Antimicrob. Chemother. 2013, 69, 827-834. [CrossRef] [PubMed]

20. Werckenthin, C. Escherichia coli Strains from Northwestern Lower Saxony Obtained as Part of the Zoonosis Monitoring (General Administrative Regulation on Zoonoses in the Food Chain). In GERMAP 2015-Report on the Consumption of Antimicrobials and the Spread of Antimicrobial Resistance in Human and Veterinary Medicine in Germany; Antiinfectives Intelligence: Rheinbach, Germany, 2016; pp. 141-142.

21. Font-Palma, C. Characterisation, kinetics and modelling of gasification of poultry manure and litter: An overview. Energy Convers. Manag. 2012, 53, 92-98. [CrossRef]

22. Kamphues, J.; Youssef, I.; El-Wahab, A.A.; Üffing, B.; Witte, M.; Tost, M. Influences of feeding and housing on foot pad health in hens and turkeys. Übers. Tierernährg 2011, 39, 147-193.

23. Bhushan, C.; Khurana, A.; Sinha, R.; Nagaraju, M. Antibiotic Resistance in Poultry Environment: Spread of Resistance from Poultry Farm to Agricultural Field; CSE: New Delhi, India, 2017.

24. Wu, Y.; Wang, Z.; Liao, X. Study on the excretion of enrofloxacin in chicken and its degradation in chicken feces. Acta Vet. Zootech. Sin. 2005, 36, 1069.

25. Chuppava, B.; Keller, B.; Meißner, J.; Kietzmann, M.; Visscher, C. Effects of different types of flooring design on the development of antimicrobial resistance in commensal Escherichia coli in fattening turkeys. Vet. Microbiol. 2018, 217, 18-24. [CrossRef] [PubMed]

26. Annex I of Council Regulation. European Commission (EC) No. 1099/2009 on the Protection of Animals at the Time of Killing. 2009; pp. 1-84. Available online: https:/ / eur-lex.europa.eu/eli/reg/2009/1099/oj (accessed on 29 March 2018).

27. Scherz, G. Carryover of Subtherapeutic Antimicrobial Dosages of Enrofloxacin and the Influence on the Development of Antibiotic Resistance of Commensal Escherichia Coli in the Intestine of Poultry. Ph.D. Thesis, University of Veterinary Medicine, Hannover, Germany, 2013.

28. CLSI. Performance Standards for Antimicrobial Disk and Dilution Susceptibility Tests for Bacteria Isolated from Animals; Approved Standard-Fourth Edition; CLSI document Vet01-A4; Clinical and Laboratory Standards Institute: Wayne, PA, USA, 2013.

29. Witte, W. Medical consequences of antibiotic use in agriculture. Science 1998, 279, 996-997. [CrossRef] [PubMed]

30. Kietzmann, M.; Baeumer, W. Oral medication via feed and water pharmacological aspects. Dtsch. Tierarztl. Wochenschr. 2009, 116, 204-208. [PubMed]

31. Da Costa, P.M.; Belo, A.; Gonçalves, J.; Bernardo, F. Field trial evaluating changes in prevalence and patterns of antimicrobial resistance among Escherichia coli and Enterococcus spp. isolated from growing broilers medicated with enrofloxacin, apramycin and amoxicillin. Vet. Microbiol. 2009, 139, 284-292. [CrossRef] [PubMed] 
32. Furtula, V.; Jackson, C.R.; Farrell, E.G.; Barrett, J.B.; Hiott, L.M.; Chambers, P.A. Antimicrobial resistance in Enterococcus spp. isolated from environmental samples in an area of intensive poultry production. Int. J. Environ. Res. Public Health 2013, 10, 1020-1036. [CrossRef] [PubMed]

33. Miranda, J.; Vázquez, B.; Fente, C.; Barros-Velázquez, J.; Cepeda, A.; Franco, C. Evolution of resistance in poultry intestinal Escherichia coli during three commonly used antimicrobial therapeutic treatments in poultry. Poult. Sci. 2008, 87, 1643-1648. [CrossRef] [PubMed]

34. Jurado, S.; Medina, A.; Ruiz-Santa-Quiteria, J.A.; Orden, J.A. Resistance to non-quinolone antimicrobials in commensal Escherichia coli isolates from chickens treated orally with enrofloxacin. Jpn. J. Vet. Res. 2015, 63, 195-200. [PubMed]

35. Schwarz, S.; Chaslus-Dancla, E. Use of antimicrobials in veterinary medicine and mechanisms of resistance. Vet. Res. 2001, 32, 201-225. [CrossRef] [PubMed]

36. Richter, A.; Hafez, H.M.; Böttner, A.; Gangl, A.; Hartmann, K.; Kaske, M.; Kehrenberg, C.; Kietzmann, M.; Klarmann, D.; Klein, G. Application of antibiotics in poultry. Tierärztl. Praxis Großtiere 2009, 37, 321-329.

37. Apajalahti, J.; Kettunen, A.; Graham, H. Characteristics of the gastrointestinal microbial communities, with special reference to the chicken. Worlds Poult. Sci. J. 2004, 60, 223-232. [CrossRef]

38. Moro, M.; Beran, G.; Griffith, R.; Hoffman, L. Effects of heat stress on the antimicrobial drug resistance of Escherichia coli of the intestinal flora of swine. J. Appl. Microbiol. 2000, 88, 836-844. [CrossRef] [PubMed]

39. Oloso, N.O.; Fagbo, S.; Garbati, M.; Olonitola, S.O.; Awosanya, E.J.; Aworh, M.K.; Adamu, H.; Odetokun, I.A.; Fasina, F.O. Antimicrobial Resistance in Food Animals and the Environment in Nigeria: A Review. Int. J. Environ. Res. Public Health 2018, 15, 1284. [CrossRef] [PubMed]

40. Ozaki, H.; Esaki, H.; Takemoto, K.; Ikeda, A.; Nakatani, Y.; Someya, A.; Hirayama, N.; Murase, T. Antimicrobial resistance in fecal Escherichia coli isolated from growing chickens on commercial broiler farms. Vet. Microbiol. 2011, 150, 132-139. [CrossRef] [PubMed]

41. Jiménez-Belenguer, A.; Doménech, E.; Villagrá, A.; Fenollar, A.; Ferrús, M.A. Antimicrobial resistance of Escherichia coli isolated in newly-hatched chickens and effect of amoxicillin treatment during their growth. Avian Pathol. 2016, 45, 501-507. [CrossRef] [PubMed]

42. Dierikx, C.M.; van der Goot, J.A.; Smith, H.E.; Kant, A.; Mevius, D.J. Presence of ESBL/AmpC-producing Escherichia coli in the broiler production pyramid: A descriptive study. PLoS ONE 2013, 8, e79005. [CrossRef] [PubMed]

43. Persoons, D.; Haesebrouck, F.; Smet, A.; Herman, L.; Heyndrickx, M.; Martel, A.; Catry, B.; Berge, A.; Butaye, P.; Dewulf, J. Risk factors for ceftiofur resistance in Escherichia coli from belgian broilers. Epidemiol. Infect. 2011, 139, 765-771. [CrossRef] [PubMed]

44. Hopkins, K.L.; Davies, R.H.; Threlfall, E.J. Mechanisms of quinolone resistance in Escherichia coli and Salmonella: Recent developments. Int. J. Antimicrob. Agents 2005, 25, 358-373. [CrossRef] [PubMed] 